\title{
1 Caste, sex, and parasitism influence brain plasticity in a social wasp
}

3 Kristine M. Gandia ${ }^{1}$, Federico Cappa $^{2}$, David Baracchi ${ }^{2}$, Mark. E. Hauber ${ }^{3}$, Laura Beani ${ }^{2 *}$ \& 4 Floria M. K. Uy ${ }^{1,4^{*}}$

5

$6 \quad{ }^{1}$ Department of Biology, University of Miami, Coral Gables, FL, USA

$7 \quad 2$ Department of Biology, University of Florence, Sesto Fiorentino, Firenze, Italy

$8 \quad{ }^{3}$ Department of Evolution, Ecology and Behavior, School of Integrative Biology, University

9 of Illinois at Urbana-Champaign, Urbana, IL, USA

$10 \quad{ }^{4}$ Department of Biology, University of Rochester, Rochester, NY, USA

11

$12{ }^{*}$ Correspondence: Floria M.K. Uy

13 Email: floria.uy@rochester.edu

14

15 *Correspondence: Laura Beani

16 Email: laura.beani@unifi.it

17

18 *These authors share senior authorship

19

20 Keywords: brain plasticity, parasite, Polistes dominula, social wasp, sensory brain regions,

21 Xenos vesparum 


\section{ABSTRACT}

23 Phenotypic plasticity is the capacity of a single genotype to exhibit different phenotypes, and can

24 be an adaptive response to specific environmental and social conditions. Social insects are

25 particularly well-suited to study plasticity, because the division of labor amongst females and the

26 different life histories of males and females are associated with specific sensory needs.

27 Here, we take advantage of the social wasp Polistes dominula to explore if brain plasticity is

28 influenced by caste and sex, and the exploitation by the parasite Xenos vesparum. Within sexes,

29 males had proportionally larger optic lobes, while females, regardless of caste, had larger

30 antennal lobes, which is consistent with sensory needs of sex-specific life histories. Within

31 castes, reproductive females had larger calyces, as predicted by their sensory needs for extensive

32 within-colony interactions and forming winter aggregations, than workers who spend more time

33 foraging for nest material and prey. Surprisingly, parasites had different effects on female and

34 male hosts. Female workers were castrated and behaviorally manipulated by female or male

35 parasites, but only showed moderate differences in relative allocation of different brain tissue

36 compared to non-parasitized workers. In contrast, the testes and behavior of parasitized males

37 were essentially unaffected, but they had smaller brains and greater relative volume of most

38 sensory brain regions than non-parasitized males. Our results are consistent with caste and sex

39 mediating brain plasticity in $P$. dominula and that the parasite's manipulation can also drive

40 differential allocation of brain regions depending on host sex. 


\section{INTRODUCTION}

Within taxa, phenotypic plasticity generates responses to environmental variation, allowing

43 for organisms with a single genotype to display a variety of adaptive phenotypes (West-Eberhard

44 2003; Whitman and Agrawal 2009). When plasticity optimizes energy allocation, it can result in

45 tradeoffs between reproduction, growth, and allometric changes in body structures (Barton and

46 Capellini 2011; Birget et al. 2017; Jokela and Mutikainen 1995). Brain plasticity, for instance,

47 has evolved across many lineages as a result of variable selective pressures acting on the

48 cognitive demands of sensory and perceptual systems (Barton et al. 1995; Barton and Harvey

49 2000; Catania 2005). Since brain tissue is energetically expensive, plasticity in specific brain

50 structures may be linked to the sensory and processing needs of adaptive behaviors

51 (Montgomery et al. 2016; Niven and Laughlin 2008; Riveros and Gronenberg 2010; Rozanski et

52 al. 2021). Investment in neural tissue may be mediated by experience (Jones et al. 2009; Riveros

53 and Gronenberg 2010), diet (Murphy et al. 2014), environmental stimuli (Burns et al. 2009),

54 tradeoffs with reproduction (Pitnick et al. 2006), and/or endocrine factors (Lendvai et al. 2013).

55 Therefore, understanding neuroanatomical plasticity can be challenging, as multiple factors may

56 drive differential allocation of brain tissue (Willemet 2013).

Social insects, which have distinct caste systems with different life histories and sensory

58 and reproductive needs (Beshers and Fewell 2001), provide the opportunity to compare plasticity

59 in brain regions while controlling for genetic background. In insect brains, visual input is

60 received and processed by the optic lobes, while olfactory input is received by the antennal lobes

61 (Anton and Homberg 1999; Gronenberg and Hölldobler 1999; Strausfeld 1989). From these

62 sensory neuropils, projection neurons convey the computed information to the mushroom bodies

63 (Akalal et al. 2006). In these higher brain centers the chemical and visual information is further 
64 processed and integrated with internal information by intrinsic neurons and finally projected to

65 premotor areas. In particular, the calyces of the mushroom bodies, acts as learning and memory

66 centers and integrate this olfactory information in the lip, the visual information in the collar, and

67 both sensory stimuli in the basal ring (Akalal et al. 2006; Ehmer and Hoy 2000; Fahrbach 2006).

68 Finally, the central complex, is implicated in spatial navigation (Honkanen et al. 2019; Le Moël

69 et al. 2019; Pfeiffer and Homberg 2014). Given that specialized behaviors in social insects are

70 associated with a range of caste-specific sensory needs, corresponding investment in neural

71 tissue is expected (Arganda et al. 2020; Ehmer et al. 2001; Gronenberg et al. 1996; O'Donnell et

72 al. 2007; Penick et al. 2021; Rehan et al. 2015; Seid et al. 2011).

The primitively eusocial paper wasp Polistes dominula provides an excellent opportunity to

74 test how brain plasticity is associated with behavioral flexibility (O’Donnell and Bulova 2017;

75 O’Donnell et al. 2018; O’Donnell et al. 2014; Pardi 1996; Rozanski et al. 2021). In this temperate

76 wasp species, the recognition of nestmates, caste, and sex relies on both chemical and visual cues

77 (Beani et al. 2019; Cappa et al. 2016; Cappa et al. 2020; Cini et al. 2019; Dani et al. 2001). Females

78 are morphologically similar and organized in a flexible caste system, according to a dominance

79 hierarchy (Pardi 1948). The queen monopolizes egg-laying (Strassmann et al. 2004), while

80 subordinate foundresses and workers are involved in nest building and defense, the rearing of

81 larvae, and foraging (West-Eberhard 1969). The reproductive caste consists of gynes (future

82 foundresses) and males which emerge in mid-summer. Gynes remain on the natal nest without

83 performing any colony tasks and then mate, form winter aggregations, and enter diapause until the

84 following spring (Reeve 1991). In contrast, males abandon the nest early after emergence, display

85 lek-behavior at landmarks, mate with gynes (Cappa et al. 2013), and die at the end of summer

86 (Beani 1996; Beani et al. 2014). 
In addition, the intimate host-parasite relationship between $P$. dominula and the strepsipteran parasite insect Xenos vesparum provides a great opportunity to explore the effect of this parasite in allocation of brain tissue (Hughes and Libersat 2018; Libersat et al. 2018). X. vesparum manipulates the neuroendocrine physiology and behavior of females (Beani 2006;

91 Hughes et al. 2004b; Strambi and Strambi 1973; Strambi et al. 1982). This parasite decreases the

92 size of the corpora allata and castrates the females, by irreversibly inhibiting ovary development

93 (Strambi and Strambi 1973). Parasitized workers abandon the colony and aggregate on selected

94 plants where parasite mating occurs (Beani et al. 2018; Hughes et al. 2004b). Parasitized males, a

95 secondary host, instead maintain their reproductive apparatus and sexual behavior (Beani et al.

96 2011; Cappa et al. 2014).

97 While brain plasticity within and across social insects has been extensively studied (Godfrey 98 and Gronenberg 2019), to our knowledge, no studies have explored plasticity within a species that

99 has morphologically similar individuals, various colony tasks, and a parasite that potentially alters

100 brain morphology. We hypothesize that the relative volume of selected brain regions reflects

101 specific sensory needs for each subset of wasps (reproductive females, female workers, and males)

102 (Rozanski et al. 2021), and that parasitic manipulation may influence brain allometry. We predict

103 higher volume of visual regions in males to detect and identify potential mates or rival males in a

104 lek, compared to females. On the contrary, we expect more olfactory processing by females

105 compared to males due to social interactions in the colony. We also predict a higher effect in brain

106 plasticity towards parasitized workers, which are castrated and show aberrant behaviors, compared

107 to parasitized males who reproduce and show no changes in behavior. Finally, we expand on studies

108 that reported reduced corpora allata in parasitized females and males compared to non-infected

109 conspecific by testing for the effect of parasite sex (Beani et al. 2017; Strambi and Strambi 1973). 


\section{METHODS}

\section{Field collection}

113 We collected reproductive females $(\mathrm{N}=10$ foundresses and $\mathrm{N}=9$ gynes $)$, along with non-

114 parasitized workers $(\mathrm{N}=10)$, workers parasitized by one Xenos female $(\mathrm{N}=11)$ or by one Xenos

115 male $(\mathrm{N}=11)$ and males parasitized by one or two Xenos males $(\mathrm{N}=9)$ during summers of 2016

116 and 2018, in the plain of Sesto Fiorentino (Tuscany, Italy). Males infected by Xenos females are

117 lacking in our data set, due to the scarcity of parasitized males, a secondary target of infection,

118 and the protandrous emergence of $X$. vesparum (Hughes et al. 2004a). Wasps from each caste

119 emerge synchronously and at specific times throughout the summer, which controls for age

120 (Molina and O'Donnell 2008) and seasonality effects that can influence brain development.

121 Non-parasitized and parasitized workers are easily distinguished by inspecting for extrusions

122 between the abdominal tergites, and parasites can be identified as female or male because of the

123 shape of their pupal sac (Fig. 1). Finally, after verifying which individuals were parasitized, their

124 abdomens were preserved and dissected in 70\% ethanol to confirm presence and sex of the

125 parasites, and ovary development predicted for each category. We preserved each head capsule

126 individually in a glyoxal fixative for subsequent histological sectioning (Prefer, Anatech Ltd,

127 Battle Creek, USA).

129 Histology and measurement of brain regions

130 We first dehydrated each head capsule with a series of increasing ethanol and acetone

131 concentrations. We then used the established concentrations for the Embed 812 resin kit

132 (Electron Microscopy Sciences, Hatfield, USA) to embed the head capsule while maintaining 
133 their brain dimensions, following the histology protocol for Polistes wasps (O’Donnell et al.

134 2015; Rozanski et al. 2021). The samples were moved repeatedly between an open-air rocking

135 shaker (Thermo Fisher Scientific, Waltham, USA) and a vacuum to improve infiltration of the

136 solvent.

137 Next, we placed each embedded head capsule in an individual plastic mold filled with the 138 same concentration of resin in an oven at $60^{\circ} \mathrm{C}$. After 72 hours, the resin was polymerized. We 139 sectioned each brain in consecutive coronal sections with a thickness of $17 \mu \mathrm{m}$ and stained the 140 tissue with toluidine blue, to visualize clearly defined boundaries for each brain region. We 141 photographed the consecutive brain sections for each specimen using a Canon EOS 5D Mark III 142 mounted on a Leica DM IL LED microscope at 4x magnification, including a scale of $1000 \mu \mathrm{m}$. 143 Using the AxioVision SE64 (Zeiss, NY, USA), we outlined the area for each individual

144 brain region. We traced the antennal lobes and the three substructures of the optic lobes:

145 medulla, lobula and lamina. We also traced the two calyx substructures process olfactory and 146 visual stimuli: lip and collar, respectively and the central complex. The remaining structures 147 were grouped as the central brain, following established methods for this species (Rozanski et al. 148 2021). Outlining of brain regions was done blind to the category for each sample. We quantified 149 each brain region for every other section per brain, as this method shows high accuracy (i.e., $<$ $1503.5 \%$ error for $34 \mu \mathrm{m}$ thick sections) (Ehmer and Hoy 2000). We then determined the volume for 151 each region by multiplying the area by the distance between sections $(34 \mu \mathrm{m})$. We generated the 152 3-D brain reconstruction by using the software RECONSTRUCT (Fiala 2005). To control for the 153 effect of head size, we measured head width. Finally, we determined the cross-sectional area of 154 the corpora allata by measuring the diameter of one of the two glands, following the method 155 previously used for this species (Strambi and Strambi 1973). 
Statistical analysis

158 We explored if differential volume in specific brain regions among phenotypes was the result of

159 changes in allometric scaling (Eberhard and Wcislo 2011; O’Donnell et al. 2013; Ott and Rogers

160 2010; Seid et al. 2011; Sheehan et al. 2019; Stöckl et al. 2016). In P. dominula, the optic lobe

161 represents on average $42 \%$ of the brain and may have an effect on relative neuropil scaling

162 (Rozanski et al. 2021). Therefore, we normalized each sensory brain region by the central brain,

163 instead of by the whole brain (Ott and Rogers 2010; Sheehan et al. 2019; Stöckl et al. 2016).

164 We used the allometric equation $y=a^{*} x^{\beta}$ for the scaling relationship between brain

165 regions $\mathrm{x}$ and $\mathrm{y}$. We then logarithmically transformed the estimates $\beta$ (slope) and $\alpha$ (intercept of a

166 regression) by using the linear equation $\log (y)=\beta \log (\mathrm{x})+\log (\mathrm{a})$, where $\log (\mathrm{a})=\alpha($ Dubois

167 1897; Huxley and Teissier 1936). Standardized Major (SMA) regression analyses were

168 calculated by using the SMATR v.3 package for R (Warton et al. 2012; Warton et al. 2006).

First, we tested for a common slope among non-parasitized phenotypes as a baseline

170 comparison, consisting of males, reproductive females and workers $\left(\mathrm{H}^{0}=\beta_{\text {males }}=\beta_{\text {reproductives }}=\right.$

$171 \beta_{\text {workers }}$ ). We implemented log-likelihood tests followed by posthoc pairwise comparisons

172 provided in the SMATR package. Allometric scaling did not differ significantly between

173 foundresses and gynes, we pooled them under a new category called "reproductives". Second,

174 we tested for a common slope among non-parasitized workers, with one female parasite and with

175 one male parasite, and between non-parasitized and parasitized males. The volume of brain

176 regions did not differ between male wasp parasitized by one or two male $X$. vesparum, so we

177 also pooled them. We compared allometric changes in the whole brain with head width, central

178 brain with whole brain, and pooled sensory regions with changes in the central brain. Finally, we 
explored the allometric relationship between each sensory brain region and central brain, following our established method for this species (Rozanski et al. 2021).

For categories that shared a Common Slope, we used log-likelihood tests to calculate the

182 Slope Index (SI) for the brain region comparisons described above. The SI determined if a brain

183 region is allometric $(\beta \neq 1)$, meaning that sensory brain region $(\mathrm{y}) /$ central brain $(\mathrm{x})$ would

184 change with size. We also used a Wald Test to calculate the Common Shift $\left(\mathrm{H}^{0}=\right.$ equal axis

185 among phenotypes), for any shift along the $\mathrm{x}$ axis. Finally, we calculated how much larger a

186 sensory region (y) is compared to the central brain (y), by using a Grade Shift Index (GSI) to

187 compare phenotypes (i.e., $\mathrm{H}^{0}=\alpha_{\text {males }}=\alpha_{\text {reproductives }}=\alpha_{\text {workers }}$ ). The GSI reflected changes in

188 intercept $\alpha$ (elevation) with no changes in the slope $\beta$. This method facilitates pairwise

189 volumetric comparisons between phenotypes (i.e., $\left.\mathrm{e}^{\alpha \text { males- } \alpha \text { reproductives }}\right)$, by implementing a Wald

190 test. For example, if GSI > 1, males had larger volume of a brain region compared to

191 reproductives, and if GSI $<1$ the relationship would be inverse. We specify the direction of

192 change for each of the analyzed categories in the results section and Supplementary Tables 1 and

193 2. Lastly, we ran a Kruskal-Wallis test with subsequent pairwise comparisons to determine

194 corpora allata growth across castes and to test the effect of both parasite and host sex.

\section{RESULTS}

197 Investment in sensory regions by caste and sex

198 All brain regions, except for the central complex showed a common slope, but had unique

199 differences in the GSI, common shift and/or SI depending on the specific region (Fig. 2., Suppl.

200 Table 1.). Males and reproductive females had proportionally larger pooled sensory regions

201 compared to workers $(\mathrm{GSI}=1.056, \mathrm{P}=0.01$ and $\mathrm{GSI}=1.036, \mathrm{P}=0.006$, respectively, Fig. 2). 
Males had proportionally smaller antennal lobes when compared to reproductive females $(\mathrm{GSI}=$ 0.87, $\mathrm{P}<0.001$ ), as an effect of both changes in elevation and a common shift (Fig. 2, Suppl. Table 1). Surprisingly, males had larger antennal lobe volume than workers $(\mathrm{GSI}=0.926, \mathrm{P}=$ 0.002). Within females, reproductives had larger antennal lobes $(\mathrm{GSI}=1.057, \mathrm{P}=0.002)$ and calyces compared to workers $(\mathrm{GSI}=1.042, \mathrm{P}=0.003)$. Males had larger optic lobes than reproductive females $(\mathrm{GSI}=1.064, \mathrm{P}=0.001)$ and workers $(\mathrm{GSI}=1.103, \mathrm{P}=<0.001$, Suppl. Table 1). Reproductives had increased optic lobe volume compared to workers $(\mathrm{GSI}=1.037, \mathrm{P}=$ 0.02, Fig. 2). Finally, workers showed an isometric increase in the central complex $(\mathrm{P}=0.052)$,

210 in contrast to a hyperallometric reduction of this navigational brain region in reproductive

211 females and males (Fig. 2).

214 Surprisingly, female workers parasitized by one female or one male $X$. vesparum showed no 215 differences in allocation of most sensory brain regions, compared to non-parasitized workers.

216 Indeed, non-parasitized workers shared a common slope with workers with a female or a male $X$.

217 vesparum, and no volumetric differences in the antennal lobes or the optic lobes (Fig. 3, Suppl.

218 Table 1). However, we did find a change in the slope index of whole brain in workers parasitized

219 by a female, compared to non-parasitized workers or parasitized by a male $(\mathrm{P}<0.001$, Fig. 3,

220 Suppl. Table 1). Workers parasitized by one female had an isometric pattern, resulting in larger

221 calyces $(\mathrm{P}=0.031)$ and collars $(\mathrm{P}=0.045)$, than non-parasitized workers and those parasitized

222 by one male. Lastly, workers with one male parasite had a hyperallometric reduction of the

223 central complex in comparison to non-parasitized workers and those parasitized by a female $(\mathrm{P}=$ $224 \quad 0.027$, Fig. 3). 
In contrast, parasitized and non-parasitized males showed differential allocation towards

226 specific brain regions. They shared a common slope and differences in grade shifts for the

227 following brain regions: whole brain, antennal brain, lip, and central complex (Suppl. Table 2).

228 Parasitized males had a proportionally smaller whole brains than non-parasitized males (GSI =

229 1.15, $\mathrm{P}<0.001$, Suppl. Table 2, Fig. 4). However, due to a common shift along the main slope

230 axis, parasitized males had proportionally large antennal lobes $(\mathrm{P}=0.01), \operatorname{lip}(\mathrm{P}=0.001)$ and

231 central complex $(\mathrm{P}<0.001)$ compared to non-parasitized males (Suppl. Table 1). In contrast, the

232 following brain regions did not show isometric growth: central brain, pooled sensory regions,

233 optic lobes, calyces and collar (Fig. 4, Suppl. Table 2). Parasitized males showed a

234 disproportionately reduced volume of the central brain $(\mathrm{P}=0.02)$, but disproportionately large

235 volume of pooled sensory regions $(\mathrm{P}=0.03)$, optic lobes $(\mathrm{P}=0.03)$, calyces $(\mathrm{P}=0.04)$, and

236 collar $(\mathrm{P}=0.02)$ compared to non-parasitized males (Fig. 4, Suppl. Table 2).

Corpora allata development according to sex, caste and parasitism

239 The corpora allata were significantly smaller in all males compared to females $\left(\chi^{2}=46.86, \mathrm{df}=\right.$

$2406, \mathrm{P}<0.001$, Fig. 5). As expected, foundresses had larger corpora allata compared to gynes and

241 workers. Posthoc pairwise tests revealed showed a trend in reduction of the corpora allata in

242 parasitized workers compared to non-parasitized workers. However, gland size did not differ

243 according to parasite sex $(\mathrm{P}=0.39)$, or between parasitized and non-parasitized males $(\mathrm{P}=0.98)$.

245 DISCUSSION

246 We provide several lines of evidence supporting the focal hypothesis that brain plasticity

247 facilitates differential sensory needs and life histories within the same species. First, reproductive 
248 females also had larger calyces compared to worker females, reflecting sensory needs associated

249 to division of labor, implying a life history-based plasticity of otherwise genetically shared

250 backgrounds in female wasps. Furthermore, genetically distinct (haploid) males and (diploid)

251 females showed a consistent and significant tradeoff in volume of the optic and antennal lobes.

252 Second, we provide novel evidence for the effect of the Xenos parasite in neural investment by

253 female and male hosts. Surprisingly, non-parasitized and parasitized workers show moderate

254 volumetric differences in brain sensory regions, while parasitized males showed a more drastic

255 effect in allocation of neural tissue compared to non-parasitized workers. Overall, our results are

256 consistent with differential investment in brain regions being advantageous across social wasp

257 species (O'Donnell et al. 2011), while it can also be driven by parasitic manipulation, which may

258 be potentially maladaptive for the host.

The observed neural tradeoffs reflect the distinct life cycles of $P$. dominula males and

260 females, similarly to previous studies in social Hymenoptera (reviewed in Beani et al. 2014).

261 Males leave their nest within a few days after emergence and gather at distinct leks to increase

262 their mating opportunities (Beani 1996). When attempting to mate, males can visually

263 distinguish between females and competing males, and between workers and gynes (Cappa et al.

264 2013; da Silva et al. 2021; de Souza et al. 2017). Therefore, higher investment in the optic lobes

265 may facilitate detection and discrimination between potential mates or male intruders in their

266 defended territories (Beani et al. 2014). Males have smaller antennal lobes, which is likely due to

267 experiencing less complex olfactory stimuli, as they do not engage in frequent social interactions

268 in the colony. In contrast, reproductive females have proportionally larger antennal lobes, lips

269 and collars, which is consistent with other studies that show sensory needs associated to division

270 of labor, interactions among nestmates, learning and memory (Ehmer and Hoy 2000; Gronenberg 
et al. 1996; Jernigan et al. 2021; Mertes et al. 2021; O'Donnell et al. 2011; Rozanski et al. 2021;

272 Uy et al. 2021). Thus, the social environment of female wasps has a wider range of chemical and

273 sensory processing cues compared to males (Beani et al. 2014). Within females, reproductives

274 had proportionally larger calyces than workers, which coincides with division of labor in these

275 social wasps (Molina and O'Donnell 2008; O'Donnell et al. 2007). Future foundresses

276 consistently engage in social interactions both within the colony and during winter aggregations,

277 utilizing visual and chemical cues towards recognition (Cini et al. 2019; Dani et al. 2001). In

278 contrast, most workers spend less time interacting with foundresses and brood on the nest, and

279 allocate more time performing tasks such as foraging for prey and building material (Gamboa et

280 al. 1978).

281 We confirmed reduced corpora allata in parasitized workers, when compared to non-

282 parasitized ones and more drastically to reproductive females (Strambi and Strambi 1973).

283 However, contrary to our expectations, parasites have milder effects in the brain architecture of

284 workers. Parasitized workers lose most of their social behavior and aggregate on specific plants

285 where they perform site-fidelity and territorial defense of resources, allowing the completion of

286 the parasite life cycle (Beani et al. 2018). This active life style most likely requires intact sensory

287 processing and cognitive abilities. By selectively acting on the neuroendocrine function of the

288 corpora allata (Strambi and Strambi 1973), the parasite may specifically disrupt the host social

289 behavior while maintaining the sensory machinery needed to survive. Thus, the parasite has

290 strong effects in castrating the female host and in inducing her social aberrant behavior, but

291 moderate effects on allocation of brain regions.

292 Noticeably, workers parasitized by one $X$. vesparum female showed larger calyces than

293 non-parasitized workers and those parasitized by one male. Interestingly, workers parasitized by 
294 one female overwinter and resemble the behavioral and physiological phenotype of

295 overwintering gynes, while workers parasitized by a male die at the end of summer like non-

296 parasitized ones (Beani et al. 2021). Male parasites also induced a hyperallometric reduction of

297 the central complex, compared to non-parasitized workers or workers parasitized by one female.

298 This difference in the central complex, which is mainly implicated in spatial navigation, is not

299 consistent with the lack of differences in behavior between workers infected by the two sexes.

300 In contrast, male parasites had a more drastic effect in the brain architecture of $P$.

301 dominula males, which act as secondary hosts. Parasitized males had significantly smaller whole

302 brains and central brains than non-parasitized males. They also showed a significant increase in

303 the volume of several sensory brain regions, including the antennal and optic lobes, and two

304 substructures of the calyx: lip and collar. Remarkably, neuroendocrine manipulation does not

305 seem to occur in parasitized males, as they can still develop their testes and attempt to mate with

306 females (Beani et al. 2017; Cappa et al. 2014). The inability to hinder male reproduction may

307 likely result in a tradeoff with brain manipulation, which is an expensive tissue to produce

308 (Keesey et al. 2020; Niven and Laughlin 2008).

309 Overall, our results demonstrate that brain plasticity is associated to sensory needs in

310 males and within female castes of $P$. dominula, but that parasitic manipulation can also drive

311 differential investment of brain regions depending on both host and parasite sex. Intriguingly,

312 parasitized workers show a strong manipulation effect of the parasite on caste determination,

313 lipid storage, and prolonged lifespan in parasitized females (Beani et al. 2021), but more

314 dampened effects on allocation of brain tissue. In turn, the reproductive apparatus and behavior

315 of parasitized males are essentially unaffected, but they experience stronger volumetric changes

316 in brain regions. However, the parasite may be relying on other manipulation mechanisms, 
317 without driving evident neuroanatomical changes in its female hosts (Libersat et al. 2018). For

318 instance, $X$. vesparum can drive changes in gene expression of a worker towards a gyne-like

319 pattern; thus, the parasite is manipulating the transcriptomic plasticity of the caste system (Geffre

320 et al. 2017). Future research in organisms that show natural plasticity in behavioral and sensory

321 needs will provide further opportunities to explore the neural mechanisms underlying parasitic

322 manipulation.

\section{ACKNOWLEDGEMENTS}

325 We thank Jamie Brunworth for assistance in quantifying brain regions. William Searcy, Al Uy

326 and members of the Uy lab provided useful feedback in early versions of the manuscript. KMG,

327 MEH and FMKU were supported by a National Academies Keck Future Initiatives Grant

328 (NAKFI). FC, DB and LB were supported by University of Florence funds. MEH is a visiting

329 fellow at the Wissenschaftskolleg zu Berlin. Samples were imported from Italy into the USA via

330 USDA permit \#128388.

\section{AUTHOR CONTRIBUTIONS}

333 LB and FC collected the wasp and parasite field samples. KMG performed histological

334 preparation of specimens and collected volumetric data. FMKU analyzed the data. KMG, LB,

335 FC and FMKU contributed to the first draft of the manuscript. All authors provided input to

336 concept and design of this project, data interpretation, along with reviewing and editing the final

337 manuscript. LB and FMKU shared senior authorship.

339 CONFLICT OF INTEREST: The authors declare no conflicts of interest. 


\section{LITERATURE CITED}

Akalal, D.-B. G., C. F. Wilson, L. Zong, N. K. Tanaka, K. Ito, and R. L. Davis. 2006. Roles for Drosophila mushroom body neurons in olfactory learning and memory. Learning \& Memory 13:659-668.

Anton, S., and U. Homberg. 1999. Antennal lobe structure, Pages 97-124 Insect Olfaction. Berlin, Heidelberg, Springer.

Arganda, S., A. P. Hoadley, E. S. Razdan, I. B. Muratore, and J. F. A. Traniello. 2020. The neuroplasticity of division of labor: worker polymorphism, compound eye structure and brain organization in the leafcutter ant Atta cephalotes. Journal of Comparative Physiology A 206:651-662.

Barton, R., A. Purvis, and P. Harvey. 1995. Evolutionary radiation of visual and olfactory brain systems in primates, bats and insectivores. Philosophical Transactions of the Royal Society of London. Series B: Biological Sciences 348:381-392.

Barton, R. A., and I. Capellini. 2011. Maternal investment, life histories, and the costs of brain growth in mammals. Proceedings of the National Academy of Sciences 108:6169-6174.

Barton, R. A., and P. H. Harvey. 2000. Mosaic evolution of brain structure in mammals. Nature 405:1055-1058.

Beani, L. 1996. Lek-like courtship in paper-wasps: 'a prolonged, delicate, and troublesome affair', Pages 113-125 in S. Turillazzi, and M. J. West-Eberhard, eds. Natural history and evolution of paper-wasps.

Beani, L. 2006. Crazy wasps: when parasites manipulate the Polistes phenotype. Annales Zoologici Fennici:564-574.

Beani, L., A.-G. Bagneres, M. Elia, I. Petrocelli, F. Cappa, and M. Lorenzi. 2019. Cuticular hydrocarbons as cues of sex and health condition in Polistes dominula wasps. Insectes Sociaux 66:543-553.

Beani, L., F. Cappa, F. Manfredini, and M. Zaccaroni. 2018. Preference of Polistes dominula wasps for trumpet creepers when infected by Xenos vesparum: A novel example of coevolved traits between host and parasite. PLoS One 13:e0205201.

Beani, L., R. Dallai, F. Cappa, F. Manfredini, M. Zaccaroni, M. C. Lorenzi, and D. Mercati. 2021. A Strepsipteran parasite extends the lifespan of workers in a social wasp. Scientific Reports 11:1-10.

Beani, L., R. Dallai, D. Mercati, F. Cappa, F. Giusti, and F. Manfredini. 2011. When a parasite breaks all the rules of a colony: morphology and fate of wasps infected by a strepsipteran endoparasite. Animal Behaviour 82:1305-1312.

Beani, L., F. Dessì-Fulgheri, F. Cappa, and A. Toth. 2014. The trap of sex in social insects: from the female to the male perspective. Neuroscience \& Biobehavioral Reviews 46:519-533.

Beani, L., D. Marchini, F. Cappa, I. Petrocelli, M. Gottardo, F. Manfredini, F. Giusti et al. 2017. Subtle effect of Xenos vesparum (Xenidae, Strepsiptera) on the reproductive apparatus of its male host: Parasite or parasitoid? Journal of Insect Physiology 101:22-30.

Beshers, S. N., and J. H. Fewell. 2001. Models of division of labor in social insects. Annual Review of Entomology 46:413-440.

Birget, P. L., C. Repton, A. J. O'Donnell, P. Schneider, and S. E. Reece. 2017. Phenotypic plasticity in reproductive effort: malaria parasites respond to resource availability. Proceedings of the Royal Society B: Biological Sciences 284:20171229. 
Burns, J. G., A. Saravanan, and F. Helen Rodd. 2009. Rearing environment affects the brain size of guppies: Lab-reared guppies have smaller brains than wild-caught guppies. Ethology 115:122-133.

Cappa, F., L. Beani, and R. Cervo. 2016. The importance of being yellow: visual over chemical cues in gender recognition in a social wasp. Behavioral Ecology 27:1182-1189.

Cappa, F., C. Bruschini, R. Cervo, S. Turillazzi, and L. Beani. 2013. Males do not like the working class: male sexual preference and recognition of functional castes in a primitively eusocial wasp. Animal Behaviour 86:801-810.

Cappa, F., A. Cini, L. Signorotti, and R. Cervo. 2020. Rethinking recognition: social context in adult life rather than early experience shapes recognition in a social wasp. Philosophical Transactions of the Royal Society B 375:20190468.

Cappa, F., F. Manfredini, R. Dallai, M. Gottardo, and L. Beani. 2014. Parasitic castration by Xenos vesparum depends on host gender. Parasitology 141:1080-1087.

Catania, K. C. 2005. Evolution of sensory specializations in insectivores. The Anatomical Record Part A: Discoveries in Molecular, Cellular, and Evolutionary Biology: An Official Publication of the American Association of Anatomists 287:1038-1050.

Cini, A., F. Cappa, I. Pepiciello, L. Platania, L. Dapporto, and R. Cervo. 2019. Sight in a clique, scent in society: plasticity in the use of nestmate recognition cues along colony development in the social wasp Polistes dominula. Frontiers in Ecology and Evolution $7: 444$.

da Silva, R. C., L. Van Meerbeeck, F. S. do Nascimento, T. Wenseleers, and C. A. Oi. 2021. Close-range cues used by males of Polistes dominula in sex discrimination. The Science of Nature 108:1-16.

Dani, F. R., G. R. Jones, S. Destri, S. H. Spencer, and S. Turillazzi. 2001. Deciphering the recognition signature within the cuticular chemical profile of paper wasps. Animal Behaviour 62:165-171.

de Souza, A. R., J. Lino-Neto, E. A. Tibbetts, S. Turillazzi, and L. Beani. 2017. The leks of Polistes dominula paper wasps: tiny abdominal spots play a critical role in male attacks toward potential rivals. Ethology Ecology \& Evolution 29:410-419.

Dubois, E. 1897. Sur le rapport du poids de l'encéphale avec la grandeur du corps chez les mammifères. Bulletins et Mémoires de la Société d'Anthropologie de Paris 8:337-376.

Eberhard, W. G., and W. T. Wcislo. 2011. Grade changes in brain-body allometry: morphological and behavioural correlates of brain size in miniature spiders, insects and other invertebrates. Advances in Insect Physiology 40:155-214.

Ehmer, B., and R. Hoy. 2000. Mushroom bodies of vespid wasps. Journal of Comparative Neurology 416:93-100.

Ehmer, B., H. K. Reeve, and R. R. Hoy. 2001. Comparison of brain volumes between single and multiple foundresses in the paper wasp Polistes dominulus. Brain, Behavior and Evolution 57:161-168.

Fahrbach, S. E. 2006. Structure of the mushroom bodies of the insect brain. Annual Review of Entomology 51:209-232.

Fiala, J. C. 2005. Reconstruct: a free editor for serial section microscopy. Journal of Microscopy 218:52-61.

Gamboa, G. J., B. D. Heacock, and S. L. Wiltjer. 1978. Division of labor and subordinate longevity in foundress associations of the paper wasp, Polistes metricus (Hymenoptera: Vespidae). Journal of the Kansas Entomological society:343-352. 
Geffre, A. C., R. Liu, F. Manfredini, L. Beani, J. Kathirithamby, C. M. Grozinger, and A. L. Toth. 2017. Transcriptomics of an extended phenotype: parasite manipulation of wasp social behaviour shifts expression of caste-related genes. Proceedings of the Royal Society B: Biological Sciences 284:20170029.

Godfrey, R. K., and W. Gronenberg. 2019. Brain evolution in social insects: advocating for the comparative approach. Journal of Comparative Physiology A 205:13-32.

Gronenberg, W., S. Heeren, and B. Hölldobler. 1996. Age-dependent and task-related morphological changes in the brain and the mushroom bodies of the ant Camponotus floridanus. Journal of Experimental Biology 199:2011-2019.

Gronenberg, W., and B. Hölldobler. 1999. Morphologic representation of visual and antennal information in the ant brain. Journal of Comparative Neurology 412:229-240.

Honkanen, A., A. Adden, J. da Silva Freitas, and S. Heinze. 2019. The insect central complex and the neural basis of navigational strategies. Journal of Experimental Biology 222.

Hughes, D. P., J. Kathirithamby, and L. Beani. 2004a. Prevalence of the parasite Strepsiptera in adult Polistes wasps: field collections and literature overview. Ethology Ecology \& Evolution 16:363-375.

Hughes, D. P., J. Kathirithamby, S. Turillazzi, and L. Beani. 2004b. Social wasps desert the colony and aggregate outside if parasitized: parasite manipulation? Behavioral Ecology 15:1037-1043.

Hughes, D. P., and F. Libersat. 2018. Neuroparasitology of parasite-insect associations. Annual Review of Entomology 63:471-487.

Huxley, J. S., and G. Teissier. 1936. Terminology of relative growth. Nature 137:780-781.

Jernigan, C. M., N. C. Zaba, and M. J. Sheehan. 2021. Age and social experience induced plasticity across brain regions of the paper wasp Polistes fuscatus. Biology Letters 17:20210073.

Jokela, J., and P. Mutikainen. 1995. Phenotypic plasticity and priority rules for energy allocation in a freshwater clam: a field experiment. Oecologia 104:122-132.

Jones, T. A., N. A. Donlan, and S. O’Donnell. 2009. Growth and pruning of mushroom body Kenyon cell dendrites during worker behavioral development in the paper wasp, Polybia aequatorialis (Hymenoptera: Vespidae). Neurobiology of Learning and Memory 92:485495.

Keesey, I. W., V. Grabe, M. Knaden, and B. S. Hansson. 2020. Divergent sensory investment mirrors potential speciation via niche partitioning across Drosophila. eLife 9:e57008.

Le Moël, F., T. Stone, M. Lihoreau, A. Wystrach, and B. Webb. 2019. The central complex as a potential substrate for vector based navigation. Frontiers in Psychology 10:690.

Lendvai, Á. Z., V. Bókony, F. Angelier, O. Chastel, and D. Sol. 2013. Do smart birds stress less? An interspecific relationship between brain size and corticosterone levels. Proceedings of the Royal Society B: Biological Sciences 280:20131734.

Libersat, F., M. Kaiser, and S. Emanuel. 2018. Mind control: how parasites manipulate cognitive functions in their insect hosts. Frontiers in Psychology 9:572.

Mertes, M., J. Carcaud, and J.-C. Sandoz. 2021. Olfactory coding in the antennal lobe of the bumble bee Bombus terrestris. Scientific Reports 11:1-14.

Molina, Y., and S. O'Donnell. 2008. Age, sex, and dominance-related mushroom body plasticity in the paperwasp Mischocyttarus mastigophorus. Developmental Neurobiology 68:950959. 
Montgomery, S. H., N. I. Mundy, and R. A. Barton. 2016. Brain evolution and development: adaptation, allometry and constraint. Proceedings of the Royal Society B: Biological Sciences 283:20160433.

Murphy, T., G. P. Dias, and S. Thuret. 2014. Effects of diet on brain plasticity in animal and human studies: mind the gap. Neural plasticity 563160.

Niven, J. E., and S. B. Laughlin. 2008. Energy limitation as a selective pressure on the evolution of sensory systems. Journal of Experimental Biology 211:1792-1804.

O'Donnell, S., M. Clifford, and Y. Molina. 2011. Comparative analysis of constraints and caste differences in brain investment among social paper wasps. Proceedings of the National Academy of Sciences 108:7107-7112.

O'Donnell, S., N. Donlan, and T. Jones. 2007. Developmental and dominance-associated differences in mushroom body structure in the paper wasp Mischocyttarus mastigophorus. Developmental Neurobiology 67:39-46.

O’Donnell, S., and S. Bulova. 2017. Development and evolution of brain allometry in wasps (Vespidae): size, ecology and sociality. Current Opinion in Insect Science 22:54-61.

O’Donnell, S., S. J. Bulova, M. Barrett, and K. Fiocca. 2018. Size constraints and sensory adaptations affect mosaic brain evolution in paper wasps (Vespidae: Epiponini). Biological Journal of the Linnean Society 123:302-310.

O’Donnell, S., S. J. Bulova, S. DeLeon, P. Khodak, S. Miller, and E. Sulger. 2015. Distributed cognition and social brains: reductions in mushroom body investment accompanied the origins of sociality in wasps (Hymenoptera: Vespidae). Proceedings of the Royal Society B: Biological Sciences 282:20150791.

O’Donnell, S., M. R. Clifford, S. J. Bulova, S. DeLeon, C. Papa, and N. Zahedi. 2014. A test of neuroecological predictions using paperwasp caste differences in brain structure (Hymenoptera: Vespidae). Behavioral Ecology and Sociobiology 68:529-536.

O’Donnell, S., M. R. Clifford, S. DeLeon, C. Papa, N. Zahedi, and S. J. Bulova. 2013. Brain size and visual environment predict species differences in paper wasp sensory processing brain regions (Hymenoptera: Vespidae, Polistinae). Brain, Behavior and Evolution 82:177-184.

Ott, S. R., and S. M. Rogers. 2010. Gregarious desert locusts have substantially larger brains with altered proportions compared with the solitarious phase. Proceedings of the Royal Society B: Biological Sciences 277:3087-3096.

Pardi, L. 1948. Dominance order in Polistes wasps. Physiological Zoology 21:1-13.

Pardi, L. 1996. Polistes: analysis of a society, Pages 1-17 in S. Turillazzi, and M. J. WestEberhard, eds. Natural history and evolution of paper-wasps, Oxford University Press Oxford.

Penick, C. A., M. Ghaninia, K. L. Haight, C. Opachaloemphan, H. Yan, D. Reinberg, and J. Liebig. 2021. Reversible plasticity in brain size, behaviour and physiology characterizes caste transitions in a socially flexible ant (Harpegnathos saltator). Proceedings of the Royal Society B 288:20210141.

Pfeiffer, K., and U. Homberg. 2014. Organization and functional roles of the central complex in the insect brain. Annual Review of Entomology 59:165-184.

Pitnick, S., K. E. Jones, and G. S. Wilkinson. 2006. Mating system and brain size in bats. Proceedings of the Royal Society B: Biological Sciences 273:719-724.

Reeve, H. K. 1991, Polistes: The social biology of wasps, Cornell University Press. 
Rehan, S. M., S. J. Bulova, and S. O'Donnell. 2015. Cumulative effects of foraging behavior and social dominance on brain development in a facultatively social bee (Ceratina australensis). Brain Behavior and Evolution 85:117-124.

Riveros, A. J., and W. Gronenberg. 2010. Sensory allometry, foraging task specialization and resource exploitation in honeybees. Behavioral Ecology and Sociobiology 64:955-966.

Rozanski, A. N., A. Cini, T. E. Lopreto, K. M. Gandia, M. E. Hauber, R. Cervo, and F. M. K. Uy. 2021. Differential investment in visual and olfactory brain regions is linked to the sensory needs of a wasp social parasite and its host. Journal of Comparative Neurology:112.

Seid, M. A., A. Castillo, and W. T. Wcislo. 2011. The allometry of brain miniaturization in ants. Brain, Behavior and Evolution 77:5-13.

Sheehan, Z. B., J. F. Kamhi, M. A. Seid, and A. Narendra. 2019. Differential investment in brain regions for a diurnal and nocturnal lifestyle in Australian Myrmecia ants. Journal of Comparative Neurology 527:1261-1277.

Stöckl, A., S. Heinze, A. Charalabidis, B. El Jundi, E. Warrant, and A. Kelber. 2016. Differential investment in visual and olfactory brain areas reflects behavioural choices in hawk moths. Scientific Reports 6:1-10.

Strambi, A., and C. Strambi. 1973. Influence du developpement du parasite Xenos Vesparum Rossi, (Insecte, Strepsiptere) sur le systeme neuroendocrinien des femelles de Polistes (Hymenoptere, Vespide) au de leur vie imaginale. Archives d Anatomie Microscopique et de Morphologie Experimentale 62:39-54.

Strambi, C., A. Strambi, and R. Augier. 1982. Protein level in the haemolymph of the wasp Polistes gallicus $L$. at the beginning of imaginal life and during overwintering. Action of the strepsiterian parasite Xenos vesparum rossi. Experientia 38:1189-1191.

Strassmann, J. E., A. Fortunato, R. Cervo, S. Turillazzi, J. M. Damon, and D. C. Queller. 2004. The cost of queen loss in the social wasp Polistes dominulus (Hymenoptera : Vespidae). Journal of the Kansas Entomological Society 77:343-355.

Strausfeld, N. J. 1989. Beneath the Compound Eye: Neuroanatomical Analysis and Physiological Correlates in the Study of Insect Vision, Pages 317-359 Facets of Vision. Berlin, Heidelberg, Springer Berlin Heidelberg.

Uy, F. M. K., C. M. Jernigan, N. C. Zaba, E. Mehrotra, S. E. Miller, and M. J. Sheehan. 2021. Dynamic neurogenomic responses to social interactions and dominance outcomes in female paper wasps. PLoS Genetics 17:e1009474.

Warton, D. I., R. A. Duursma, D. S. Falster, and S. Taskinen. 2012. smatr 3-an R package for estimation and inference about allometric lines. Methods in Ecology and Evolution 3:257-259.

Warton, D. I., I. J. Wright, D. S. Falster, and M. Westoby. 2006. Bivariate line-fitting methods for allometry. Biological Reviews 81:259-291.

West-Eberhard, M. 1969. The social biology of polistine wasps. Miscellaneous Publications of the Museum Zoolology Universty of Michigan 140:1-101.

West-Eberhard, M. J. 2003, Developmental plasticity and evolution, Oxford University Press.

Whitman, D. W., and A. A. Agrawal. 2009. What is phenotypic plasticity and why is it important. Phenotypic plasticity of insects: Mechanisms and Consequences:1-63.

Willemet, R. 2013. Reconsidering the evolution of brain, cognition, and behavior in birds and mammals. Frontiers in Psychology 4:396. 


\section{FIGURE LEGENDS}

567 Figure 1. Study system: a female brain, the abdomen of a parasitized female, and X. vesparum

568 parasites. A) Frontal view of a 3-D reconstructed brain of a female Polistes dominula. The

569 sensory brain regions are color coded: substructures of the optic lobes (blue), antennal lobes

570 (yellow), lip (bright red), collar (dark red) and the central complex (white). All sensory regions

571 are normalized by the central brain (gray). For reference, the subesophageal zone is shown in

572 bright pink and the mushroom body peduncles in light red. Scale bar $=500 \mu \mathrm{m}$. B) A host

573 abdomen shows the cephalothorax of a neotenic male $X$. vesparum (top) and one female $X$.

574 vesparum pupa (bottom) extruding from the tergites. C) Same larvae of X. vesparum after being

575 dissected from the host's abdomen: male parasite on top and female on the bottom. Figures B

576 and $\mathrm{C}$ are scaled (scale bar $=2 \mathrm{~mm})$.

578 Figure 2. Comparison of the investment in sensory regions by sex and caste. The volume of each 579 brain region was log-transformed, and each dot represents one individual. The males are depicted

580 in black, reproductives (gynes and foundresses) in dark orange and workers in blue. The

581 corresponding colored lines represent the slope for each category, and each dot represents an

582 individual. Given that most comparisons shared a common slope, see Supplementary Table 1. for

583 full Standardized major axis (SMA) results.

585 Figure 3. Comparison of the investment in sensory regions by parasitized and non-parasitized

586 workers. Categories are depicted as non-parasitized workers (blue), workers parasitized by one

587 female $X$. vesparum (dark gray) and workers parasitized by one male $X$. vesparum (light gray).

588 The corresponding color-coded line represents the slope for each category and each dot 
589 represents an individual. Some comparisons shared a common slope, see Supplementary Table 1

590 for full statistical results.

591

592 Figure 4. Comparison of the investment in sensory regions by parasitized (black) and non-

593 parasitized males (gray). SMA fits are log-transformed per categories with the lines based on

594 intercepts and slopes (black for parasitized and grey for non-parasitized males). Most volumetric

595 comparisons did not share a common slope, see Supplementary Table 2 for full SMA tests.

597 Figure 5. Corpora allata size in reproductive females, workers, males, parasitized workers and

598 parasitized males. The cross-sectional area of the corpora allata was calculated by measuring its

599 diameter in microns and normalized with head size. Wasp categories are color coded: found

600 (foundresses), gynes, work (workers), work $\mathrm{fmm}_{\mathrm{fm}}$ (workers with 1 female parasite), work $\mathrm{k}_{1 \mathrm{~m}}$ (worker

601 with 1 male parasite), males and male $1 \mathrm{~m}$ (male with 1 male parasite).

602 


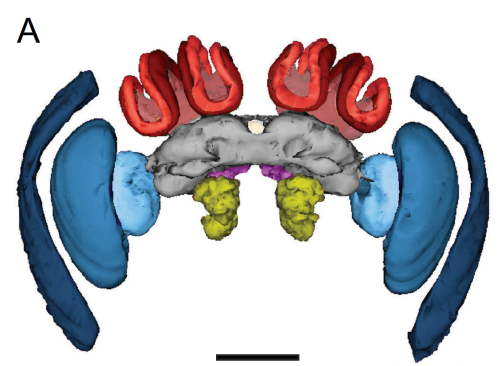

603

\section{Figure 1.}

605
B

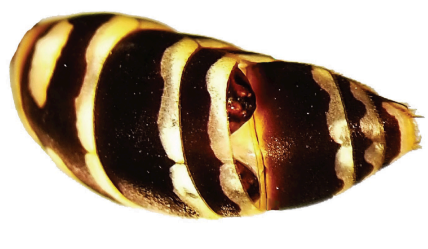

C

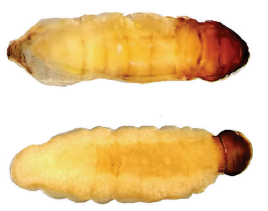



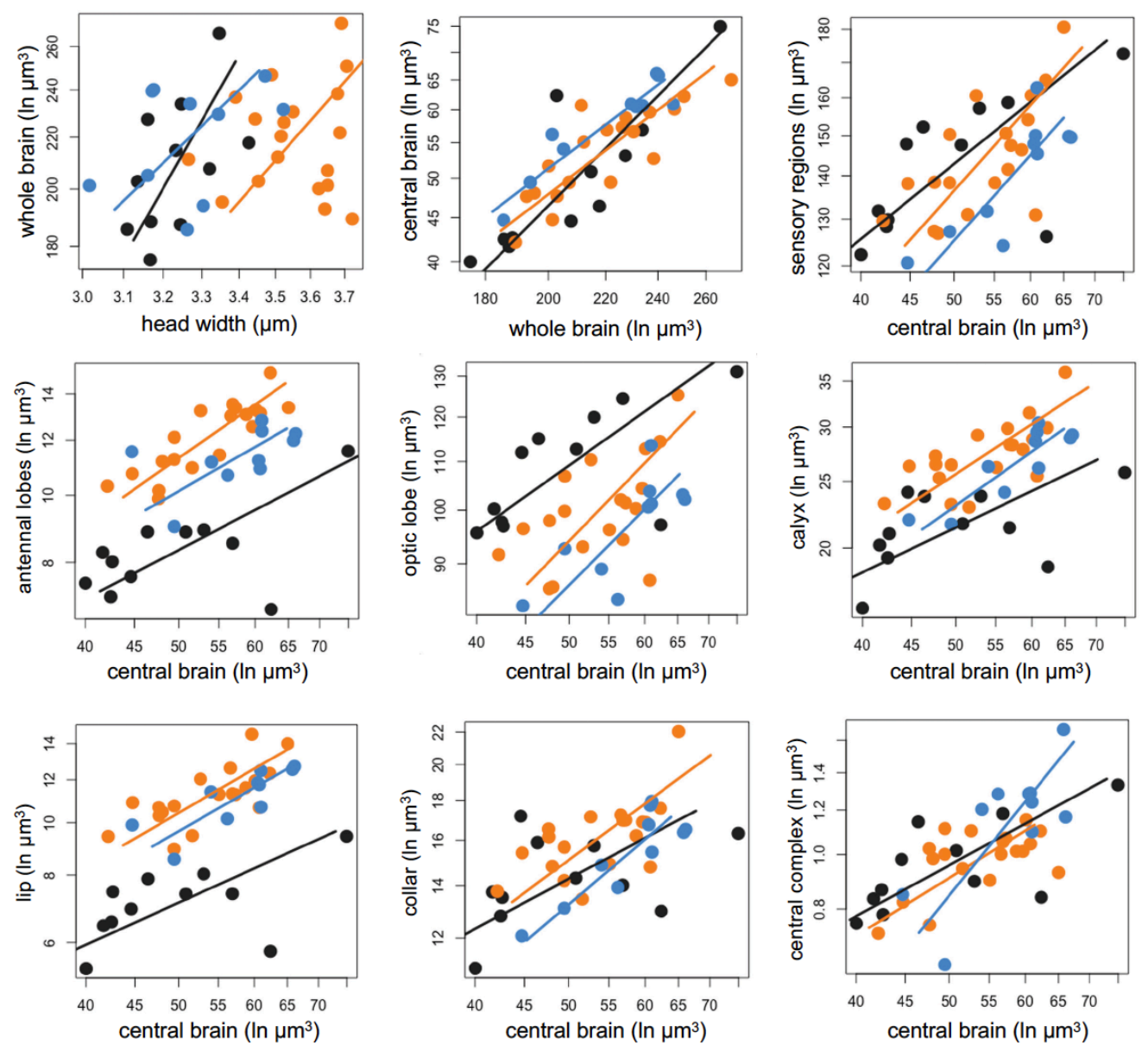

- male reproductive worker

\section{Figure 2.}



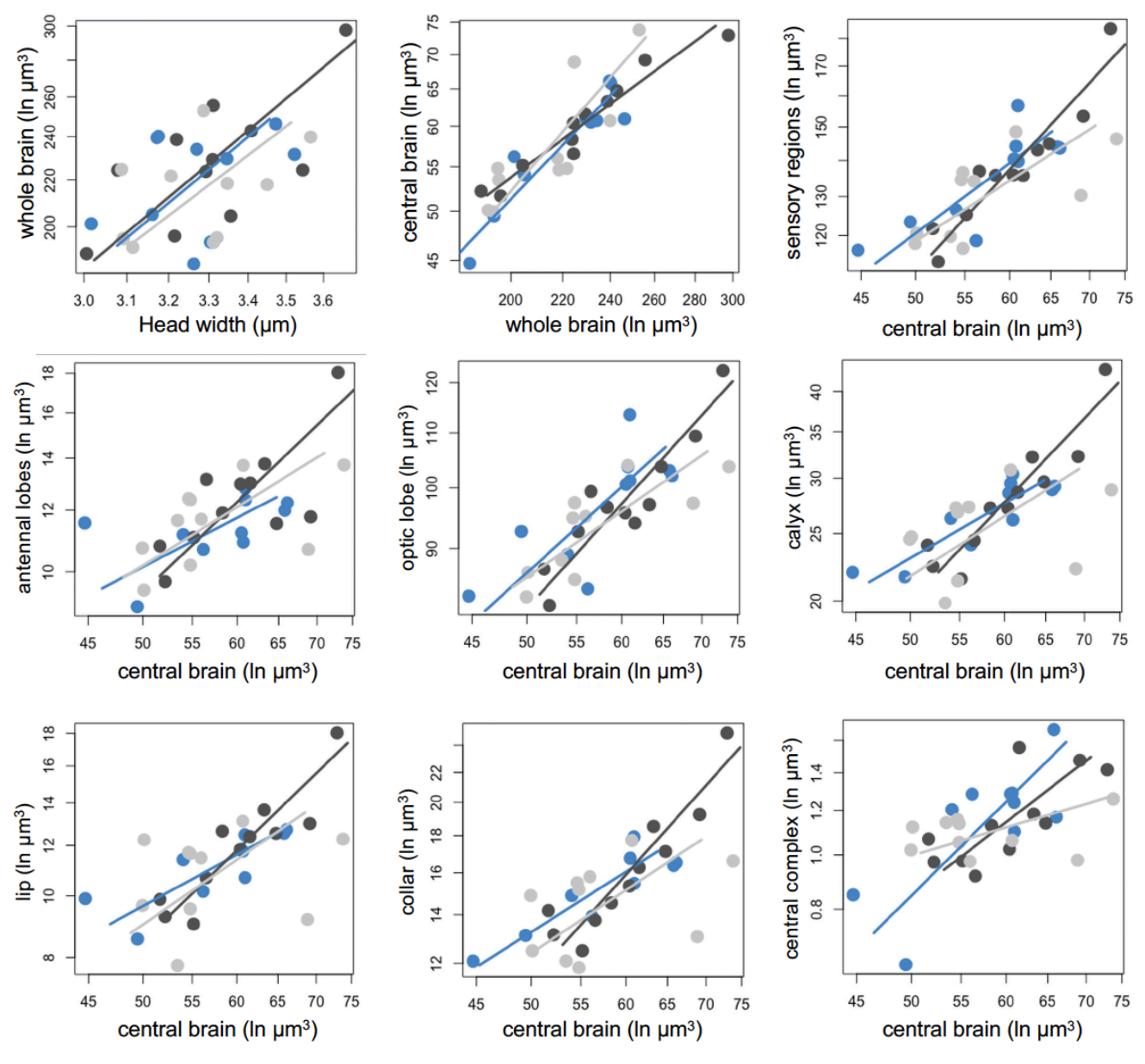

- worker $\bullet$ worker $1 \mathrm{fp} \bullet$ worker $1 \mathrm{mp}$

Figure 3. 

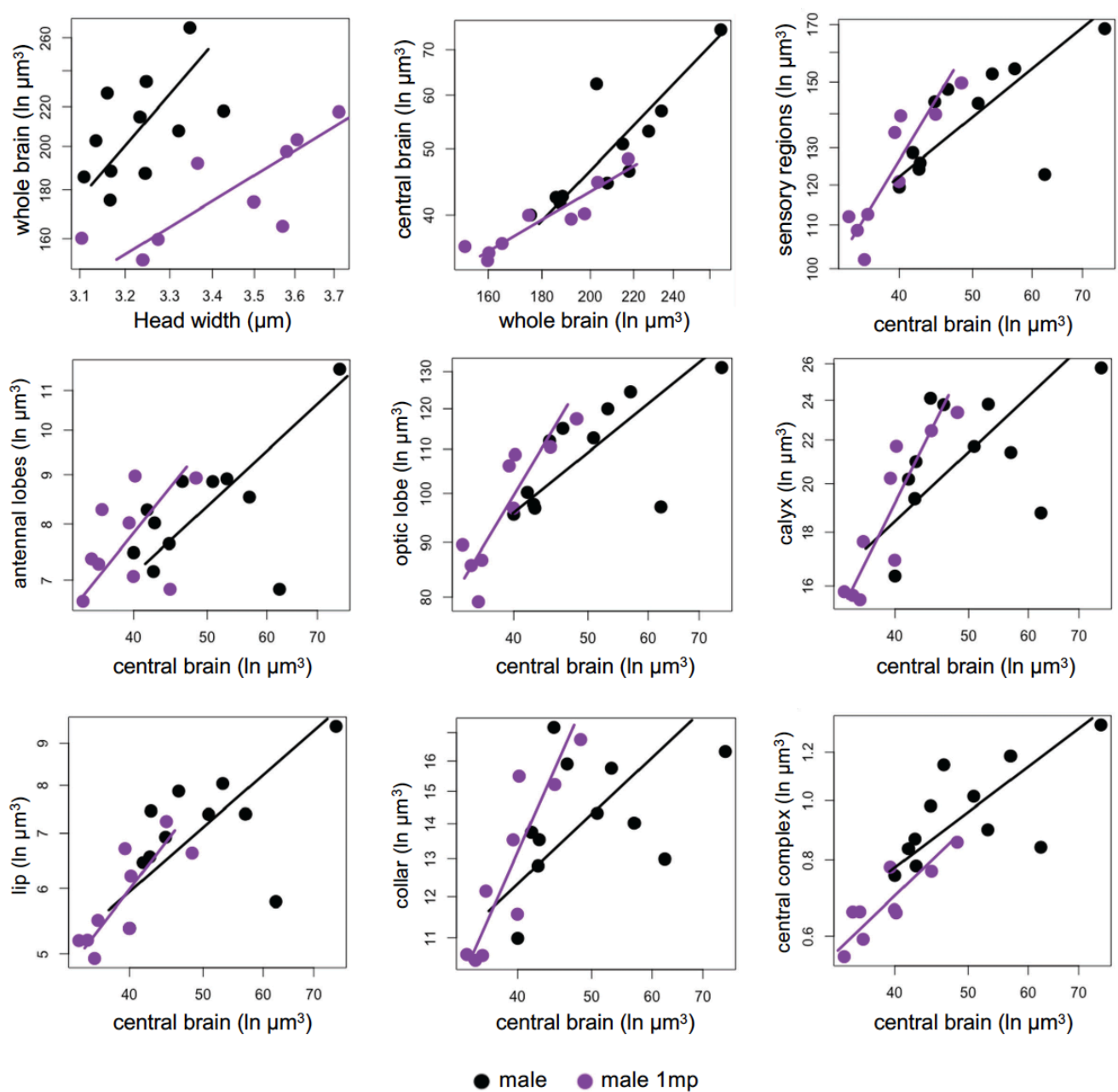

611

\section{Figure 4.}




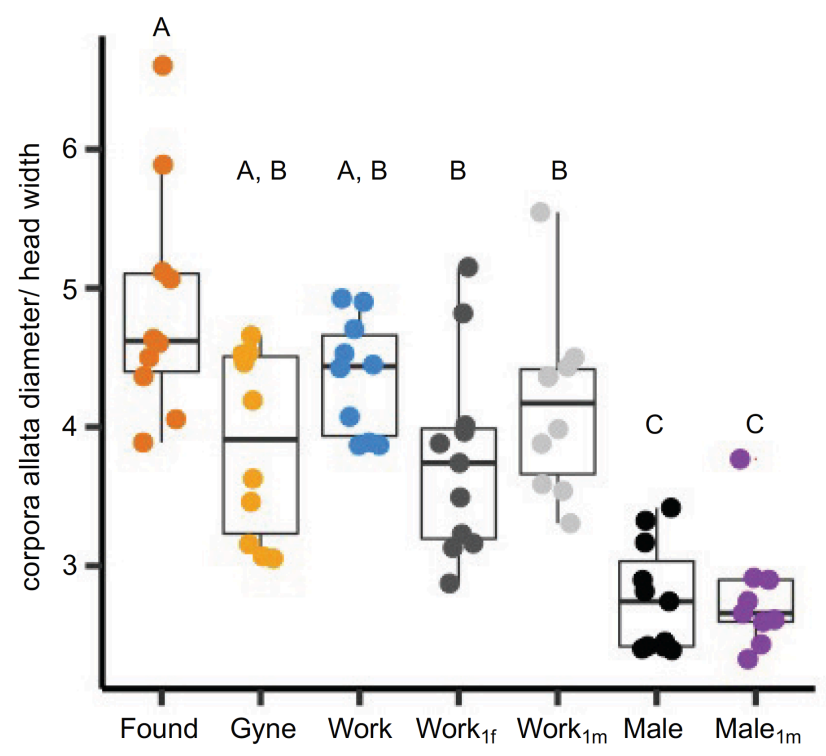

613

614 Figure 5. 